\title{
Calígrafos y Tipógrafos indígenas en la Nueva España
}

\author{
Marina GARONE GRAVIER \\ Universidad Nacional Autónoma de México. Instituto de Investigaciones Bibliográficas \\ Seminario Interdisciplinario de Bibliología \\ mgarone@marinagarone.com
}

Recibido: Agosto 2013

Aceptado: Octubre 2013

Resumen: Las menciones sobre el uso del alfabeto latino por parte de los indígenas americanos se encuentran en diversas obras que abordan el contacto y la conquista del Nuevo Mundo, desde las crónicas de las órdenes religiosas hasta los diversos trabajos filológicos que elaboraron los frailes y curas. Todas expresan de algún modo que el sistema alfabético, si bien transformó el significado original de las textos indígenas, funcionó en favor de las comunidades nativas en la medida de que esos actores sociales pronto hicieron uso efectivo del nuevo sistema de registro. En el caso de la Nueva España la participación de los indígenas en la producción libresca se manifestó claramente en múltiples aspectos: no sólo por sus labores como informantes, traductores y correctores de las obras de los misioneros, sino en la concepción visual misma y la producción material específica de los manuscritos e impresos coloniales. Tomando en consideración el fenómeno antes citado, en este trabajo se analizará el papel que jugaron los calígrafos y tipógrafos indígenas en la configuración de sus registros escritos en clave alfabética, labor que permitió configurar una nueva cultura libresca y escrita de tradición indoamericana. Para abordar este tema en primer lugar haré una sucinta descripción de la educación caligráfica y tipográfica que recibieron los indígenas mexicanos con posterioridad a la conquista americana; en segundo lugar se comentarán algunos ejemplos concretos de manuscritos e impresos en los que participaron indígenas y por último presentaré un breve resumen del léxico relativo al universo de lo escrito y lo libresco presentes en vocabularios novohispanos en lenguas indígenas.

Palabras clave: calígrafos; historia del libro; indígenas; México; tipógrafos.

\section{Indigenous Calligraphers and Typographers in the New Spain}

\begin{abstract}
The references about the use of the Latin alphabet by the Native Americans can be found in many books that address the contact and conquest of the New World, from the chronicles of religious orders to the various philological works produced by monks and priests. All of them express, in some way, that the alphabetic system, even if it transformed the original meaning of the Indian texts, worked in favor of the native communities to the extent that these social actors soon made effective use of the new registration system. In the case of the New Spain, indigenous participation in book production was clearly manifested in many ways: not only by their labor as informants, translators and correctors of the missionaries' works, but also because they
\end{abstract}


participated activelly in the visual design and material production of colonial manuscripts and printed books. Taking the phenomenon mentioned above into cosideration, this paper will analyze the role played by calligraphers and typographers in shaping the indigenous written records in alphabetical model, a work that allowed bookish shape of a new American Indian written tradition. To address this issue, first I will do a brief description of calligraphic and typographic training received by Mexican Indians after the American conquest. Secondly, I will give and discuss some concrete examples of manuscripts and printed books where indigenous people participated and, finally, I will introduce a brief summary of the lexicon relative to the written and the book universe, present in the vocabularies for indigenous languages.

Keywords: calligraphers; book history; indigenous; Mexico; typographers.

\section{INTRODUCCIÓN}

Las menciones sobre escribas indígenas y su extraordinaria capacidad de adaptación a la escritura con caracteres del alfabeto latino se encuentran a lo largo de la literatura sobre contacto y conquista. Ellas son muestra de que la tecnología alfabética, aunque ocasionó indudables fracturas en el continuum identitario de las culturas nativas y transformó los procesos de semiosis de sus "narrativas", también funcionó en favor de las comunidades locales.

De esta forma, lejos de leerse esta forma de registro importada como una imposición aplastante, debemos considerarla como una aportación europea dentro del proceso de contacto, importación que permitió a las distintas culturas indígenas registrar y conservar una parte importante de su patrimonio lingüístico, histórico y cultural que de otra forma no habría sobrevivido hasta nuestros días. La participación de los indígenas en la producción libresca se manifestó en múltiples aspectos: tanto en su labor de informantes, traductores y correctores del trabajo filológico de los frailes como en la concepción visual y la producción material de los manuscritos e impresos coloniales.

La tradición prehispánica de producción de amoxtlis se combinó, renovó y modificó por el modo de registro alfabético y la producción tipográfica y de esa interacción surgieron nuevos modelos estéticos y originales soluciones editoriales para los textos en las lenguas autóctonas. Por esas razones, para entender cabalmente la dimensión histórica, cultural y lingüística de la producción libresca novohispana en lenguas indígenas, especialmente la que se produjo entre los siglos XVI y XVII, es menester analizar el papel que jugaron los calígrafos y tipógrafos indígenas en la configuración de sus propias lenguas escritas.

Para abordar este tema, en primer lugar haremos una sucinta descripción de la educación caligráfica y tipográfica que recibieron los indígenas mexicanos, haciendo énfasis en los usos que dieron a dichos saberes y habilidades y los ámbitos donde los desarrollaron. En segundo lugar presentaremos ejemplos de manuscritos e impresos en los que participaron indígenas en diversos grados. Todos están vinculados directa o indirectamente con el Colegio de la Santa Cruz 
de Tlatelolco. Por último presentaremos un resumen de la producción léxica relativa a la cultura escrita que hemos encontrado en vocabularios novohispanos, ya que para nosotros son una prueba tangible de las concepciones de las representaciones de "lo escrito y lo libresco" que se configuraron durante la época colonial.

\section{CALIGRAFÍA INDÍGENA EN CONTEXTOS RELIGIOSO Y ADMINISTRATIVO}

Durante la colonia, los escribas indígenas trabajaron en dos áreas bien diferenciadas: la religiosa y la administrativa. En el caso de la escritura religiosa, los indígenas fueron apoyo de los cronistas y misioneros, fuente de información de sus culturas y copistas de sus tradiciones. La escritura pronto se convirtió en una vía de comunicación bicultural y a los frailes les resultó de suma utilidad que algunos indígenas fueran instruidos especialmente en aspectos caligráficos. Los indios tuvieron una excelente capacidad para imitar todo género de modelos de escritura (Pazos, 1973), y sobre esto existen menciones del padre Toribio de Benavente, Motolinía, quien dice que:

[...] a escribir se enseñaron en breve tiempo, porque en pocos días que escriben luego contrahacen la materia que les dan sus maestros, y si el maestro les muda otra forma de escribir, como es cosa muy común que diversos hombres hacen diversas formas de letras, luego ellos mudan también la letra y la hacen de la forma que les da su maestro (Benavente, 2000: 360).

Por esta referencia sabemos que las caligrafías de los frailes sirvieron de modelos de referencia para los indios. Benavente informa además de la elaboración de letreros o cartelones en los que anunciaban las fiestas religiosas, en letras grandes de dos palmos, que colgaban en las torres de las iglesias, a la manera de inscripciones monumentales romanas. Pero al parecer los indios también intentaron imitar la forma y disposición de los textos impresos. El mismo fraile describió cómo un indio copió una bula:

[...] y sacóla tan al natural, que la letra que hizo parecía el mismo molde, porque el primer renglón era de letra grande, y abajo sacó la firma ni más ni menos, y un Jesús con imagen de Nuestra Señora, todo al propio que parecía no haber diferencia al molde de la otra letra, y por cosa notable y primera la lleva un española Castilla (Benavente, 2000: 360).

Entre los ámbitos donde se dio esta educación caligráfica están como ya dijimos, las escuelas para indios. A principios de 1527, fray Pedro de Gante fundó 
la escuela de San José de los Naturales. Esta fundación se debió a la necesidad de educar en los valores cristianos a una elite indígena y de realizar imágenes para el culto. Para la educación visual y manual se hicieron venir de Flandes, España e Italia modelos de pintura, escultura, grabados y libros impresos. Esto permitió que los indígenas comenzaran a interiorizarse con el uso de los caracteres latinos y los diversos modelos caligráficos: letra humanística, gótica, griega y notación musical. Por lo tanto, es lógico pensar que si hubo una escuela que formaba a los indios en aspectos manuales hubiera cierta estandarización de modelos escritos.

Los escritos producidos entonces adoptaron las características de los libros europeos en distintos formatos: pliegos sueltos, estampas pequeñas con imágenes religiosas, quedando prácticamente en desuso el formato de biombo tradicional de los amoxtlis de la cultura prehispánica. A pesar de la escasez que aquejó la mayor parte del periodo colonial, se empleó papel europeo y en menor proporción papel de tradición indígena ${ }^{1} \mathrm{y}$ pigmentos mineral, vegetal y animal ${ }^{2}$.

Además de la religiosa, la otra gran área de trabajo de los amanuenses indígenas fue la escritura administrativa. El papel de estos escribanos de diversas etnias en sus propias comunidades fue de suma importancia ya que funcionaron literalmente de puente entre los grupos nativos y los españoles. Su trabajo en ese contexto fue hacer censos de población, delimitación de tierras y mapas, litigios de herencia, descripción de genealogías y linajes, y cobro de tributos, por mencionar algunos géneros textuales. En esas producciones escritas no fue infrecuente el empleo simultáneo de glosas alfabéticas y pictogramas prehispánicos ${ }^{3}$, hasta bien entrado el siglo XVIII.

Las escribanías y notarías formaban a sus propios amanuenses, pero la enseñanza se limitó en esos casos a los estilos de letra de carácter cursivo como la procesal, procesal encadenada y cancilleresca. Aunque encontramos testimonios en diversas lenguas, la mayor parte de los documentos producidos están en náhuatl, idioma que funcionó como lengua franca y universal de la Nueva España.

\footnotetext{
${ }^{1}$ Tanto de amate como de maguey.

${ }^{2}$ Los tlapalli o colores de la paleta náhuatl eran: rojo, negro, amarillo, blanco, verde y ocres. El azul fue usado en la tradición escriptoria maya. Sobre este punto recomiendo leer el texto de Arellano Hoffmann, op.cit.

${ }^{3}$ El sistema prehispánico de escritura se usó para referir lugares, es decir como topónimos, así como sustituto y complemento del sistema numérico y calendárico de tradición europea.
} 


\subsection{LOS INDIOS IMPRESORES ${ }^{4}$}

Además de la educación en lecto-escritura, los indios recibieron formación más específica en otras materias librescas: encuadernación ${ }^{5}$, impresión tipográfica y grabado ${ }^{6}$.

Aunque en general tenemos información sobre la educación técnica y artesanal que se impartió en los colegios franciscanos ${ }^{7}$, también es posible encontrar referencias de otras órdenes religiosas: agustinos, jesuitas y dominicos. Respecto de los primeros, Hans Lenz comenta la iniciativa de la orden agustina para establecer un molino de papel al sur de la ciudad de México, con el que se procuraría proveer de aquel insumo a la orden para la producción de obras de adoctrinamiento (Lenz, 1990: 80-83). Por lo que toca a los jesuitas, en la carta del provincial Antonio de Mendoza al general de la orden jesuita Claudio Aquaviva (Tepotzotlán, 1585) entre otros pedidos se puede leer el siguiente:

También estará aquí muy bien una emprenta; y se podrá imprimir cualquier cosa, sin más costa que la del papel y tinta. Porque estos indios tienen estraño ingenio para todos estos oficios. Y no hay otro modo, para poderse imprimir el

\footnotetext{
${ }^{4}$ Diversos autores han tratado en mayor o menor medida el tema de los indios impresores de México: Joaquín García Icazbalceta presenta algunas menciones en su Bibliografía mexicana del siglo XVI, México, FCE, 1954 y también Isabel Grañén Porrúa en "El ámbito socio-laboral de las imprentas novohispanas" en Anuario de Estudios Americanos, XLVII, 1991; finalmente Nora Jiménez Hernández da interesantes referencias en Marina Mantilla Trolle y Nora Jiménez Hernández (coords.), Colección de Lenguas Indígenas. Biblioteca Pública del Estado de Jalisco Juan José Arreola, Guadalajara, Universidad de GuadalajaraColegio de Michoacán, 2007, 394 pp.

5 En cuanto a la encuadernación, sabemos por el inventario de 1584 del Colegio de Tlatelolco que allí se encontraban diversos instrumentos que nos permiten pensar que también en esta materia los indígenas auxiliaron a los frailes. El inventario de entrega de los bienes del Colegio de Tlatelolco a Diego Ruiz, su nuevo mayordomo, estaba firmado por los padres Molina y Sahagún. Los instrumentos eran: una cuchilla grande, dos prensas de madera, un martillo de aplanar grande de hierro, un cepillo de hierro, dos punzones de hierro, un punzón de golpe, una gubia, dos pares de tijeras pequeñas, tres cosedores, un compás, una caja de cuchillos carniceros, un cepillo de madera, unas tijeras de zapatero, un martillo de hierro pequeño, tres hierros para pintar la encuadernación, una sierra y una piedra de batir. En García Icazbalceta, Joaquín, Nueva Colección de Documentos para la Historia de México. V. Códice Mendieta, México 1899.

${ }^{6}$ El grabado en el contexto de la edición en lenguas indígenas no será tratado en este ensayo, sin embargo, cabe mencionar que hemos desarrollado este tema en: "La imagen en las ediciones novohispanas en lenguas indígenas (siglos XVI-XIX)", propuesta para el III Encuentro de la Sociedad Mexicana de Historiografía Lingüística A.C., octubre 2008.

${ }^{7}$ Por lo que se refiere específicamente al papel de los franciscanos y en particular, del obispo fray Juan de Zumárraga, para la venida de la imprenta al Nuevo Mundo ver Román Zulaica Gárate en Los Franciscanos y la imprenta en México en el siglo XVI, México, UNAMIIB, 1991, $373 \mathrm{pp}$.
} 
vocabulario otomí, y el flos sanctorum mexicano; porque costará los ojos de la cara; y hai muy poca salida dellos (Zubillaga, 1958: 702-722).

A pesar de estas expresiones los jesuitas no tendrían imprenta propia sino hasta el siglo XVIII cuando se establecería la del Colegio de San Ildefonso (1748-1767) ${ }^{8}$. Y finalmente, en relación con los dominicos podemos decir que el vocabulario en lenguas indígenas más explícito en cuanto al registro de términos vinculados con labores de imprenta es el diccionario zapoteco de fray Juan de Córdova, impresor en México por Ocharte y Ricardo en 1578.

Aunque las menciones a las habilidades manuales de los indios en materia tipográfica son de principios del siglo XVII, deseamos traerlas a colación porque se refieren explícitamente al Colegio de Tlatelolco. En el prólogo del Sermonario en lengua mexicana, de fray Juan Bautista (México, Diego López Dávalos, 1606:prólogo) el autor nos informa que: "[...] Diego Adriano, natural de esta Ciudad de Tlatilulco, fue muy gran latino, y tan hábil que aprendió a componer, y componía en la Emprenta en qualquier lengua, tan bien y tan expeditamente como lo pudiere hacer qualquier Maestro por diestro que fuera en este Arte." El fraile se refería al latín, al castellano y al náhuatl, aunque no hay que descartar que también se refiriera a alguna otra lengua indígena, por ejemplo el otomí. Más adelante Bautista da otros nombres:

[...] No me ha sido de menor importancia la ayuda y continua comunicación de Agustín de la Fuente, natural también de Santiago de Tlatilulco, y Maestro del Colegio de la Santa Cruz [...] El qual por desseo de ver impresso el Sermonario que escribió, ha aprendido a componer, y compone admirablemte, y assí va casi todo compuesto en la Emprenta por el: que no ha sido de poca ayuda, para que vaya bien correcto, que no lleva errata de importancia.

Mendieta comentaba respecto de los indios de aquel colegio franciscano que, aunque hubo oposición a que se enseñara latín a los indios ${ }^{9}$, esa formación era necesaria porque: "con estos colegiales latinos aprendieron su lengua perfectamente por arte los que bien la supieron, y con ayuda de ellos tradujeron en la misma lengua las doctrinas y tratados que han sido menester para enseñamiento de todos los indios, y los impresores con su ayuda los han impreso, que de otra manera no pudiera" (Mendieta, 1999: s/p).

${ }^{8}$ Sobre la historia de esta imprenta mexicana recomiendo ver: Martha Ellen Whittaker, Jesuit Printing in Bourbon Mexico City: The Press of the Colegio de San Ildefonso, 1748-1767, University of Berkeley, California, 1998, tesis doctoral.

9 Jerónimo López escribió al Emperador que el haber enseñado a leer y escribir a los indios "había sido muy dañoso como el diablo" (20 de octubre de 1541). En José Toribio Medina, Historia de la imprenta en los antiguos dominios españoles de América y Oceanía, Tomo I, prólogo de Guillermo Feliu Cruz; complemento bibliográfico de José Zamudio Z. Disponible en línea. 
Esto mismo queda manifiesto en la Primera parte del sermonario, dominical, y sanctoral en lengua mexicana, de fray Juan de Mijangos (México, Juan de Alcázar, 1624:páginas preliminares sin numerar) donde puede leerse: "Gran parte deste [libro] compuso un oficial, que no sabía la lengua, por muerte del que lo comenzó a componer, y esta fue la ocasión de haber erratas".

El aprendizaje tipográfico de los indios también se puso de manifiesto en documentos inquisitoriales. En carta del impresor flamenco Cornelio Adrián César dirigida a los Inquisidores aproximadamente en 1602, además de denunciar los malos tratos que recibía por parte de fray Juan Bautista, guardián del Colegio de Tlatelolco, donde purgando su condena, expresa lo siguiente:

[...] pretende [el guardián, dé] a entender y mostrar mi arte a los indios, para que de mi lo depriendan y sepan porque después de ellos sabido, y en cumplido el tenor de mi sentencia (siendo Dios servido) no podré ganar un pan con el dicho mi oficio, porque sabido de mi los dichos indios, no es de ningún provecho, y pues, V. S. siempre me ha hecho merced y caridad, no ser justo, siendo V. S. servido la reciba yo con tanto daño ${ }^{10}$.

Al parecer no solamente en el contexto monástico los indios tuvieron participación en las labores de imprenta. En una cédula sobre oficios vendibles del año 1582, se describe la producción de naipes en Nueva España y se indican los distintos rubros de producción y sus costos. En ella se precisa además el pago de 3 tomines por una gruesa de doce docenas de naipes para "los indios que los imprimen y engrudan"". Asimismo se cuenta con la escritura de aprendizaje del indiezuelo Diego Alonso, natural del barrio de Santiago de Tlatelolco, de 14 años de edad, quien entra por aprendiz del oficio de impresor con el licenciado Juan Blanco de Alcázar, en 1626. El contrato se establece por tiempo de cuatro años durante los cuales se le iba a enseñar el oficio de imprimir, tirar, batir, componer y todo lo demás de este arte hasta que sea oficial y pueda trabajar en la parte y lugar que quisiere ${ }^{12}$.

Sin embargo, a partir del primer tercio del siglo XVII comienza a verse una disminución de la participación de los hablantes locales en las labores de imprenta, perceptible por ejemplo en el aumento del tamaño de las fe de errata.

${ }^{10}$ La carta no está fechada, pero posiblemente fue escrita en 1602. Archivo General de la Nación, Inquisición, tomos 65, núm. 5, 252 A.5, 236 A.18.

${ }^{11}$ Documento consultado en Archivo Histórico Nacional de España: Diversos-colecciones 25, N. 56.

${ }^{12}$ México 1626/11/20 Archivo de Notarías de la Ciudad de México, Notario Juan Pérez de Rivera, libro 3362 bis I, f. 3709-370v. En los dos primeros años del aprendizaje, el impresor se comprometía a darle cada mes un peso y medio y en los dos años restantes, dos pesos mensuales. Asimismo debía garantizarle la comida, y el vestido y tenerlo en su casa. Además debía pagarle lo que solía ganar un oficial. 


\section{LA EPOPEYA DEL ALFABETO LATINO EN LA NUEVA ESPAÑA}

\subsection{LAS FORMAS DE LA LETRA: MODELOS ESCRITOS ${ }^{13}$}

Aunque aún no contamos con información precisa acerca de los manuales de escritura que circularon en la Nueva España antes de $1585^{14}$, sabemos que durante el siglo XVI ya se habían producido varios en Europa. Para los fines de este trabajo, sólo diremos que habían aparecido quince tratados italianos y cinco españoles, que son las dos tradiciones escritas que con seguridad llegaron al Nuevo Mundo ${ }^{15}$. En espera de hacer un cotejo más exhaustivo de los del siglo XVI y compararlos con las caligrafías de los documentos manuscritos indoamericanos, esos libros podrían ser las fuentes formales de modelos de escritura que tuvieron los calígrafos indígenas. El estudio comparativo de estos manuales y los manuscritos, nos permitirán conocer la filogénesis de algunos modelos en América, especialmente el de la escritura cancilleresca.

${ }^{13}$ Esta información ha sido tratada más ampliamente en Marina Garone Gravier: "Sahagún's Codex and Book Design in the Indigenous Context", Gerhard Wolf y Joseph Connors (eds.), Colors between Two Worlds. The Florentine Codex of Bernardino de Sahagún, Florence, Villa I Tatti, 2011, pp.156-197.

${ }^{14}$ Guillermo Tovar de Teresa menciona que en la biblioteca de Luis Lagarto estaban los tratados de Vespasiano y Palatino, sin embargo debemos recordar que este calígrafo llegó a la Nueva España en 1585, es decir cuando ya se habían producido numerosos manuscritos en lenguas indígenas; en Un rescate de la fantasia: el arte de los Lagarto, iluminadores novohispanos de los siglos XVI y XVII, México, El Equilibrista-Turner, 1988. Por su parte José Torre Revelo sólo consigna envíos para el siglo XVII en "Algunos libros de caligrafía usados en México en el siglo XVII", Historia Mexicana, V (oct.-dic.), 1955, pp. 220-227. Nosotros hemos revisado las listas de libros del siglo XVI que consigna Fernández del Castillo y no hemos encontrado referencias sobre manuales de escritura.

${ }^{15}$ En Italia aparecieron los tratados de Fanti (1514), Arrighi (con varias ediciones, la primera de las cuales es de 1524), Tagliente (1524), Verini (1526), Carpi (1535), Palatino (1540), Ruano (1554), Vespasiano (1554), Cresci (1560), Hercolani (1571), Monte Regale (1576), Scalzini (1600?), Verovio (1587), Curiote (1593) y Rossi (1598). Por lo que toca a los producidos en España podemos mencionar el de Iciar (cuya primera edición es de 1548), Madariaga (1565), Lucas (1580), de la Cuesta (1589) y Pérez (1600). Las referencias completas se pueden consultar en: Becker, David P. The Practice of Letters. The Hofer Collection of Writing Manuals 15141800, Harvard College Library, 1997. 8 1/2 x 11. XXIII, 127 pp. y Joyce Whalley, The Pen's Excellencie. A Pictorical History of Western Calligraphy, Taplinger, New York, 1982. 


\subsection{LOS ESTILOS CALIGRÁFICOS EN NUEVA ESPAÑA DURANTE EL SIGLO XVI Y PRINCIPIOS DEL XVII}

Por lo que se refiere a los estilos de letras empleados por los indígenas en la Nueva España, es posible advertir dos grandes grupos de escrituras: a) las usuales en los ámbitos administrativos (a este grupo pertenecen las variantes documentales de la gótica: cortesana, procesal, procesal encadenada) y b) las empleadas con una intensión libraria y ornamental (góticas, mayúsculas romanas y humanísticas) ${ }^{16}$. En este trabajo nos detendremos en el segundo conjunto de estilos por ser el que ofrece mayores variaciones formales y que implica un innegable entrenamiento no sólo en aspectos técnicos, sino también en cuanto a valoraciones estéticas.

A) Escritura gótica. Estas escrituras derivan de la carolina y al igual que ésta, es una escritura internacional ya que se usó en diversas regiones de Europa entre los siglos XII y XV, aunque con variantes nacionales. Entre las variantes que se pueden identificar están las góticas librarias y las documentales, de las cuales derivan a su vez otros tipos. Aunque en algunos lugares su uso perduró hasta el siglo XVII, fue sustituida paulatinamente por las escrituras humanísticas.

B) Escritura capital o mayúscula. Proviene de la epigrafía monumental del periodo romano y se consolida en la época del emperador Augusto. El ductus es pausado, es decir, no es una escritura rápida o cursiva. Emplea un sistema de dos líneas con la proporción que dan el triángulo, el rectángulo y el círculo. Dentro de estas capitales librarias se pueden distinguir las cuadradas y las rústicas. Las cuadradas se componen a partir de un módulo cuadrado pero realizado de forma caligráfica. También hallamos capitales rústicas cuya mayor diferencia con el tipo cuadrado es que no son tan verticales ni simétricas. La rústica es el prototipo de la escritura normal romana.

C) Escritura humanística. Dentro de este grupo se pueden distinguir la escritura del periodo humanístico clásico (del siglo XIV al XVI) y la del humanístico tardío (del siglo XVI a la primera mitad del XVIII). En el primero está la letra redonda, también conocida como formada, la cursiva minúscula, la cancilleresca, y las mercantiles y notariales. El primer tipo tiene mayúsculas y minúsculas con un eje de composición bastante vertical y algunos rasgos caligráficos. Por su parte, las cancillerescas son una simplificación de la escritura gótica propia de las cancillerías italianas que, durante el siglo XV y gracias al influjo de la letra humanística redonda, se convertirá en una variante de la humanística cursiva.

${ }^{16}$ En este trabajo hemos seguido a manera de orientación general la clasificación propuesta por Ángel Riesco en Introducción a la paleografía y la diplomática general, Madrid, Síntesis, 2000, cap. 2, pp. 33-48. 


\subsection{BREVÍSIMA RELACIÓN DEL SCRIPTORIA Y LA IMPRENTA DEL COLEGIO DE TLATELOLCO. EL SCRIPTORIA DEL COLEGIO DE TLATELOLCO}

Al hablar del scriptoria del Colegio de Tlatelolco, Miguel León Portilla indica que en el establecimiento se produjeron variedad de obras entre las que sobresale el Códice Florentino ${ }^{17}$. Los Huehuetlatolli fueron recogidos por fray Bernardino y más tarde formarían parte del libro sexto de la Historia General de las cosas de la Nueva España (SAHAGÚN, II, fol. 215d.). En 1548, el virrey Antonio de Mendoza solicitó al scriptoria del Colegio de Tlatelolco un mapa de la ciudad de México $^{18}$. El mapa, de grandes proporciones, presenta las tradiciones cartográficas renacentista y mesoamericana. Por su parte el Libellus de medicinalibus indorum herbis escrito por el médico náhuatl Martín de la Cruz y puesto en latín por Juan Badiano, es un herbario en el que se representaron plantas de México y la descripción de sus propiedades. Este libro fue dedicado a Francisco de Mendoza, hijo del virrey, en 1552 y actualmente se encuentra en la Biblioteca del Museo Nacional de Antropología. Finalmente, el Códice Tlatelolco ofrece una crónica de varios hechos como la sublevación indígena que se conoce como la Guerra del Mixtón ${ }^{19}$. Además de estos notables documentos se conservan numerosos manuscritos, en su mayoría de temas religiosos.

Ahora bien, más allá del valor histórico, etnográfico y lingüístico de estos textos, lo que nos interesa señalar es que la producción sostenida de documentos de diversa naturaleza nos hace pensar que los escribas del Colegio recibieron una formación específica en cuanto al diseño y configuración visual de textos. En el proceso de elaboración del libro, el escriba tenía presente y observaba puntualmente los preceptos que regulaban el ejercicio de su profesión y que constituían su propia sensibilidad estética. Los amanuenses podrían aplicar estas reglas siguiendo sus gustos personales, siguiendo el consejo de alguien más o una tradición local, factor que podía tener gran peso. En la decisión de la organización visual del texto intervenía el contenido de la obra y el fin al que era destinada la misma. Por lo tanto estudiar estos factores nos permite acercarnos a las ideas de la proporción y organización espacial del escrito subyacente entre los escribas indígenas.

17 "El scriptoria tenía alguna semejanza con lo que en náhuatl se conocía como Tlahcuiloyan «lugar donde se escribe y pinta», es decir donde se producían los amoxtlis." Miguel León Portilla, Códices, México, Aguilar, p. 104.

\footnotetext{
${ }_{18}$ Actualmente ese mapa se encuentra en la Biblioteca de la Universidad de Upsala, en Suecia.

${ }^{19}$ León Portilla, op. cit., p. 106.
} 


\subsection{LA IMPRENTA DE TLATELOLCO Y LA PRODUCCIÓN IMPRESA DE FRAY JUAN BAUTISTA}

En el Colegio de Santa Cruz de Tlatelolco funcionó la imprenta que había sido de Pedro Ocharte y que estuvo a cargo, sucesivamente, de su viuda (1597-1598), de Melchor Ocharte (1599-1601) y de Luis Ocharte Figueroa $(1600-1601)^{20}$. A partir de 1601 y hasta 1611 funcionó también en Tlatelolco la imprenta de Diego López Dávalos, que no era otra que la de su suegro, el punzonista Antonio de Espinosa. Desde 1611 y hasta 1615, la imprenta de López Dávalos pasó a manos de su viuda, María de Espinosa, quien nombró como cajista a Cornelio. El impreso más antiguo que salió del Colegio de Tlatelolco es una hoja del calendario de 1598, realizada por Cornelio en la imprenta de la viuda de Pedro Ocharte (León, 1917: 55), y los últimos libros fueron los impresos del taller de López Dávalos que funcionó allí.

Traeremos a colación algunas obras de fray Juan Bautista quien, como nos lo presenta Ascensión Hernández, podría ser considerado como un eslabón entre los autores del siglo XVI y XVII porque en su formación se cristalizaron los valores humanísticos no sólo de la orden, sino del colegio de Tlatelolco en su último periodo de esplendor. Al igual que sus correligionarios Molina y Sahagún, Bautista fue prolífico escritor aunque sólo hayan llegado a nuestros días siete impresos de su autoría. Contó para sus labores evangélicas con numerosas obras de otros religiosos y estuvo en estrechísimo contacto con el Colegio de Tlatelolco, siendo guardián de la casa desde 1598 hasta 1603, y entre ese último año y 1609, definidor (Hernández de León Portilla, 1988: 49-50).

A finales del siglo XVI, más precisamente en 1599, sale a la luz el primer impreso de fray Juan Bautista: el Confessionario en lengua mexicana y castellana (Tlatelolco, Melchor Ocharte, 1599). Este Confesionario, junto con el de fray Alonso de Molina son los únicos que se conservan del siglo XVI. En esa obra merece especial atención la referencia que hace el autor acerca de la mala calidad de la edición a la que tuvo que atenerse, en particular en materia de imágenes y tipografía, también describe cómo se siguen usando imágenes como medio para iniciar las pláticas doctrinales.

A inicios del siglo XVII Bautista publica Advertencia para los confessores de los naturales [...] (Tlatelolco, Melchor Ocharte 1600) que Hernández ha descrito como un tratado de casuística de la confesión con innumerables preguntas y citas de autoridades. En 1604 aparece De la miseria y brevedad de la vida del hombre

${ }^{20}$ Estas informaciones están más ampliamente desarrolladas en José Toribio Medina, La imprenta en México, México, UNAM, 1990, VIII tomos y Marina Garone Gravier, "La tipografía de la Casa Plantiniana: impacto y trascendencia en las imprentas hispanomexicanas", en Un mundo sobre papel. Libros y grabados flamencos en el imperio hispanoportugués, siglos XVIXVIII, coordinación de Wermer Thomas y Thomas Stols, Bruselas, ACCO, 2009, pp. 317-338. 
en lengua mexicana [...], primera de tres obras que aparecerá en la casa de Diego López Dávalos, que, al igual que el Sermonario dos años más tarde, participa del espíritu del ascetismo barroco. También del fraile es: Vida y milagro del bienaventurado Sant Antonio de Padua [...] (1605). Finalmente apareció impreso su sermonario A Jesucristo S. N. Ofrece este sermonario en Lengua Mexicana [...] (1606). El prólogo del Sermonario es particularmente importante para nosotros ya que allí proporciona amplia información sobre los indígenas que lo auxiliaron a él y a otros religiosos como traductores, escribanos y componedores en la imprenta.

\section{VOCABLOS EN LENGUAS INDÍGENAS RELATIVOS A LA CULTURA ESCRITA Y LIBRESCA}

Además de las menciones explícitas que hemos presentado sobre la colaboración de los indios en los aspectos de la materialidad de los textos, es interesante constatar que en algunos vocabularios novohispanos se consignaron términos relacionados específicamente con la cultura escrita y el mundo libresco: encontramos términos relacionados con la escritura, la impresión, la iluminación y la encuadernación, además de una serie de objetos e insumos. Para nosotros estos términos son muestra clara de la necesidad de comunicación que existió sobre estos temas entre europeos e indígenas hablantes de diversas lenguas. Fueron particularmente útiles para nosotros los artículos de Úrsula Thiemer-Sachse para el zapoteco y Carmen Arellano Hoffmann para el náhuatl, ${ }^{21}$ a los que hemos procurado seguir y añadir información ${ }^{22}$.

La búsqueda lexicográfica se realizó en las siguientes obras: ${ }^{23}$ Vocabulario de la lengua de Michoacán de Maturino Gilberti (México, Juan Pablos, 1559); Vocabulario en lengua castellana y mexicana de Alonso de Molina (México, Antonio de Espinosa, 1571); Vocabulario en lengua zapoteca, de Juan de Córdova (México, Ocharte-Ricardo, 1578); Vocabulario en lengua mixteca, de Francisco Alvarado (México, Pedro Balli, 1593) ${ }^{24}$; Arte breve de la lengua otomí y

${ }^{21}$ Úrsula Thiemer-Sachse, "Los complejos 'libros e imprenta' en el vocabulario españolzapoteco (1578) de Juan de Cordova" en Del autor al lector, Carmen Castañeda (coord.), Miguel Ángel Porrúa-Ciesas, México, 2002 y Carmen Arellano Hoffmann, "El escriba mesoamericano y sus utensilios de trabajo. La posición social del escriba antes y después de la conquista española", en De tlacuilos y escribanos: estudios sobre documentos indigenas coloniales del centro de México, Xavier Noguez y Stephanie Wood (coords.), Zamora, Michoacán, El Colegio de Michoacán; Zinacantepec, México: El Colegio Mexiquense, 1998, pp. 219-256.

${ }^{22}$ Para el zapoteco, además de los términos presentados por la autora, hemos localizado los siguientes: cartilla, lector, papel de estraza, pluma para escribir, prensa, tinta y tintero.

${ }^{23}$ De las obras referidas, se consultaron las ediciones originales que están en las Bibliotecas: Nacional de México, Pública de Guadalajara, Palafoxiana y Cervantina (ITESM).

${ }^{24}$ El ejemplar original consultado en la Biblioteca Pública de Guadalajara termina en la letra $\mathrm{T}$ porque está mutilado. Hemos completado la búsqueda en las siguientes ediciones: 
vocabulario trilingüe, de Alonso Urbano (manuscrito en español, náhuatl, otomí de 1605); Arte de la lengua tepehuana, con un vocabulario, confesionario y catecismo, de Benito Rinaldini (México, viuda de Jose Bernardo de Hogal, 1743) y Paradigma apologético y noticia de la lengua huasteca. Con vocabulario, catecismo y administración de sacramentos de Carlos de Tapia Zenteno (México, Imprenta de la Biblioteca Mexicana, 1767).

\subsection{LOS TÉRMINOS DE CULTURA ESCRITA Y SUS INCIDENCIAS EN LOS IDIOMAS INDÍGENAS}

Estandarización de los campos. A los fines de contabilizar las entradas aclarando mínimas divergencias hicimos algunos ajustes en el registro de entradas: Librillo se cambió por libro pequeño (mixteco); cobertor libro por cobertor de libro (mixteco y purépecha); impresión así por impresión así (acto de imprimir) (otomí); letra (lo mismo) por letra (purépecha); escritura contra alguno por escritura contra otro (mixteco); papel de estraza o de la tierra por papel de estraza (mixteco); comienço de libro por principio de libro (zapoteco); cuaderno de hojas por cuaderno (zapoteco) y carta escrita por carta (otomí).

Para su contabilidad, los términos fueron organizados de dos maneras: cronológica, en relación con su fuente original y, de forma descendente, por su número de apariciones. El primer criterio obedece a que sabemos que algunos vocabularios fueron usados como modelos de otros y de esta forma podría haber un efecto en cascada de transferencia conceptual de unos a otros. Por ejemplo, el alto número de entradas del otomí se debe a que en la elaboración de su obra trilingüe Urbano recurrió al vocabulario grande de fray Alonso de Molina (1571).

Hay un total de 151 entradas que están relacionadas con la cultura escrita ${ }^{25}$. Pliego de papel es el concepto con mayor número de entradas en las lenguas estudiadas (5 de 6) y le siguen hoja de libro, cobertor de libro y libro pequeño (5 cada una) y 18 palabras tienen 4 incidencias ( $12 \%$ del total). Estas palabras se refieren a:

Vocabulario en lengua de Mechuacan, fray Maturino Gilberti; transcripción paleográfica Agustin Jacinto Zavala, Zamora, Mich.: El Colegio de Michoacán: Fideicomiso Teixidor, c1997, 634 pp., y Diccionario de la lengua tarasca o de Michoacán / por Maturino Gilberti; reimpreso bajo la dir. y cuidado del Dr. Ernesto Ramos Meza; nota prel. de Jose Bravo Ugarte, México: [s.n.], 1962, 518 pp., Colección siglo XVI; 9, Facsímil de: Bocabulario en lengua de mechuacan/ compuesta por el reverendo padre fray Maturino Gilberti, 1559.

${ }^{25}$ El total de entradas por lenguas es como sigue: Purépecha: 71 entradas; náhuatl 72; otomí: 72; mixteco: 55; zapoteco 45; tepehuano: 17 y huasteco: 4. 
a) Características y tipos de libros (libro de cuentas, cartapacio);

b) Actividad de lectura, escritura, corrección y venta de libros (lector que lee, librero que vende libros, escritor que compone, corregir escritura, escribano público);

c) Tipo y característica de la escritura (escribir por minuta, escritura verdadera, escritura falsa, escritura de propia mano, escribir matriculando, escribir firmando);

d) Lugares, objetos y acciones vinculadas con libros e impresión (librería, letra, impresión, la imprenta, batir papel, encuadernar libro).

Un 30\% de las entradas (47 términos) están representadas en la mitad de las lenguas analizadas, los campos que integran estos términos incluyen los anteriores y son más específicos, como por ejemplo: tablilla para escribir, margen de libro, mano de papel, imprimir libros, imprimir como libros, impresor tal, impresión así (acto de imprimir).

El 16\% (24 términos) aparecen en dos lenguas: imprenta o letra, escribanía, título de libro, tintero para tinta, imprimir, tinta para escribir, hoja pequeña, lector, hoja de pergamino, componer obra, canto o escritura, forma de letra, doblar papel, deletrear, carátula de papel, pluma, el cañón, pergamino, péndola o peñola, escritura contra otro, papel de estraza, escritor como quiera, letrero de letras, letrado, carátula generalmente, escritorio, carta, lo propio que papel.

Por último el $31 \%$ de los términos (54) aparecen en sólo una lengua indígena. A manera de resumen podemos decir que entre un 54 y $47 \%$ de los términos figuran en la mayoría de las lenguas.

\section{CONCLUSIONES PRELIMINARES}

Como hemos podido observar, el universo de lo escrito y lo libresco durante el primer y segundo siglo de vida colonial implica aspectos variados de los cuales, me atrevería a decir que los alfabéticos (entendido como los fenómenos visuales de la expresión escrita en manuscritos e impresos) han sido los menos estudiados. Como hemos explicado en trabajos previos ${ }^{26}$, las pugnas por el establecimiento de las ortografías de las lenguas indígenas no fueron un ámbito exclusivamente de los autores, sino que en el proceso de afianzamiento de las escrituras en las lenguas locales participaron directa y decididamente los propios hablantes y escribientes indígenas.

${ }^{26}$ Marina Garone Gravier, "Nuevos retratos para las viejas palabras: libros novohispanos en lenguas indígenas" en El libro y sus historias, Istor, Revista del Centro de Investigaciones y Desarrollo Económico (CIDE), México, año VIII, número 31, invierno de 2007, pp. 102-117 y "Semiótica y tipografía. Edición y diseño en lenguas indígenas, ” Páginas de Guarda. Revista de Lenguaje, Edición y Cultura Escrita, No. 5, Enero-Junio 2008, Buenos Aires, Argentina, pp. 122-138. 
En la Nueva España, la incorporación de la tecnología alfabética se dio de forma constante y progresiva, lo que no excluyó la presencia de conflictos de identidad, resistencia e imposición. Sin embargo, es posible decir que esta adopción llegó a constituir una verdadera herramienta de autoexpresión de las comunidades indígenas. La educación caligráfica y los modelos escritos a los que tuvieron acceso los distintos escribas locales fueron diversos y contrastados: desde mayúsculas rústicas romanas hasta minúsculas cancillerescas, letras griegas y notas de música; para usos religiosos, etnográficos, administrativos y mercantiles. De todos ellos tomaron sus estructuras y en algunos casos, las recrearon con interpretaciones propias, modificando algunas proporciones y combinando estilos. El resultado de esas producciones permitiría visualizar una especie de arqueología de la escritura latina en el nuevo continente. La epopeya del alfabeto no se detuvo en las manos de los indios, en todo caso cobró nueva vitalidad con ellas. Después de haber experimentado los procesos de apropiación y resignificación, el alfabeto, la escritura y los libros se indianizaron.

\section{FUENTES DE CONSULTA}

ARCHIVO DE NOTARÍAS DE LA CIUDAD DE MÉXICO. México 1626/11/20, Notario Juan Pérez de Rivera, libro 3362 bis I, f. 3709-370v.

ARCHIVO GENERAL DE LA NACIÓN, Inquisición, tomo 65, núm. 5, 252 A.5, 236 A.18.

ARCHIVO HISTÓRICO NACIONAL DE ESPAÑA: Diversas-colecciones 25, N. 56.

ARELLANO HOFFMANN, Carmen. "El escriba mesoamericano y sus utensilios de trabajo. La posición social del escriba antes y después de la conquista española". En: Xavier Noguez y Stephanie Wood (coords.). De tlacuilos y escribanos: estudios sobre documentos indígenas coloniales del centro de México. Zamora, Michoacán: El Colegio de Michoacán; Zinacantepec, México: El Colegio Mexiquense, pp. 219-256.

BECKER, David P. (1997). The Practice of Letters. The Hofer Collection of Writing Manuals 1514-1800, Harvard College Library, $127 \mathrm{pp}$.

BENAVENTE, Toribio de (2000). Historia de los indios de la Nueva España, Capítulo XII. Esteva Fabregat, Claudio (ed.). Madrid: Dastin, colección Crónicas de América.

GARCÍA ICAZBALCETA, Joaquín (1939). Nueva Colección de Documentos para la Historia de México. V. Códice Mendieta, México; citado por Manuel Romero de Terreros, Encuadernaciones artísticas mexicanas, México: SRE, 1939.

GARCÍA ICAZBALCETA, Joaquín (1954). Bibliografía mexicana del siglo XVI, México: FCE.

GARONE GRAVIER, Marina (2007). "Nuevos retratos para las viejas palabras: libros novohispanos en lenguas indígenas" en El libro y sus historias, Istor, 
Revista del Centro de Investigaciones y Desarrollo Económico (CIDE). México, año VIII, no 31, pp. 102-117.

GARONE GRAVIER, Marina (2008). "Semiótica y tipografía. Edición y diseño en lenguas indígenas," Páginas de Guarda. Revista de Lenguaje, Edición y Cultura Escrita. Buenos Aires, Argentina, no 5, Enero-Junio, pp. 122-138.

GARONE GRAVIER, Marina (2009). "La tipografía de la Casa Plantiniana: impacto y trascendencia en las imprentas hispanomexicanas". En: Wermer Thomas y Thomas Stols (coords.). Un mundo sobre papel. Libros y grabados flamencos en el imperio hispanoportugués, siglos XVI-XVIII. Bruselas: ACCO, 2009, pp. 317-338.

GARONE GRAVIER, Marina (2011). "Sahagún's Codex and Book Design in the Indigenous Context". En: Gerhard Wolf y Joseph Connors (eds.), Colors between Two Worlds. The Florentine Codex of Bernardino de Sahagún. Florence: Villa I Tatti, 2011, pp.156-197.

GILBERTI, Maturino (1962). Diccionario de la lengua tarasca o de Michoacán, reimpreso bajo la dir. y cuidado del Dr. Ernesto Ramos Meza; nota prel. de José Bravo Ugarte, México: [s.n.], 518 p, Colección siglo XVI; 9, Facsímil de: Bocabulario en lengua de mechuacan/ compuesta por el reverendo padre fray Maturino Gilberti, 1559.

GILBERTI, Maturino (1997). Vocabulario en lengua de Mechuacan, transcripción paleográfica Agustín Jacinto Zavala, Zamora, Mich.: El Colegio de Michoacan, Fideicomiso Teixidor, $634 \mathrm{pp}$.

GRAÑÉN PORRÚA, Isabel (1991). "El ámbito socio-laboral de las imprentas novohispanas" en Anuario de Estudios Americanos, no 48, pp. 49-94.

HERNÁNDEZ DE LEÓN PORTILLA, Ascensión (1988). Tepuztlahcuilolli. Impresos en náhuatl. Historia y Bibliografía. México: UNAM- IIFl, tomo 1, pp. 49-50.

LENZ, Hans (1990). Historia del papel en México y cosas relacionadas (15251950). México: Miguel Ángel Porrúa, pp. 80-83.

LEÓN, Nicolás (1917). "Un impreso mexicano del siglo XVI, no conocido", en Boletín de la Biblioteca Nacional de México, vol. XII, no 2, p. 55.

LEÓN-PORTILLA, Miguel (2003). Códices. México: Aguilar, p. 104.

MANTILLA TROLLE, Marina; JIMÉNEZ HERNÁNDEZ, Nora (coords.) (2007). Colección de Lenguas Indígenas. Biblioteca Pública del Estado de Jalisco Juan José Arreola, Guadalajara: Universidad de Guadalajara; Colegio de Michoacán, $394 \mathrm{pp}$.

MEDINA, José Toribio (1989). La imprenta en México, México: UNAM, VIII tomos.

MEDINA, José Toribio (2000). Historia de la imprenta en los antiguos dominios españoles de América y Oceanía, Tomo I. Feliu Cruz, Guillermo (prol.); Zamudio Z, José (complemento bibliográfico). Edición digital basada en la edición de Santiago de Chile, Fondo Histórico y Bibliográfico José Toribio Medina, $1958<\mathrm{http}: / /$ www.cervantesvirtual.com/FichaObra.html?Ref=4137/>. 
[Consulta realizada el 15 de octubre de 2008]. Localización: $<$ http://www.cervantesvirtual.com/FichaObra.html?Ref=4137>.

MENDIETA, Jerónimo de 1999. Historia eclesiástica indiana; Joaquín García Icazbalceta (ed.). Alicante: Biblioteca Virtual Miguel de Cervantes, (Edición digital a partir de la edición de Joaquín García Icazbalceta, México: Antigua Librería, 1870). Libro cuarto, Capítulo XV. De la fundación del Colegio de Santa Cruz, que se edificó en la ciudad de México para enseñar a los indios en todo ejercicio de letras $<$ http://www.cervantesvirtual.com/servlet/SirveObras/ 12038305328923728654435/ index.htm $>$ [Consulta realizada el 15 de octubre de 2008].

MORENO DE LOS ARCOS, Roberto (1966). "Guía de obras en lenguas indígenas existentes en la Biblioteca Nacional", en Boletín de la Biblioteca Nacional de México, tomo XVII, enero-junio, núms. 1 y 2, pp. 21-210.

MUT, Antonio (1992). "Fórmulas españolas de la tinta caligráfica negra de los siglos XIII a XIX y otras relacionadas con la tinta (reavivar escritos contra las manchas y la goma glasa)", en El papel y las tintas en la transición de la información. Primeras Jornadas Archivísticas, del 12 al 16 de mayo de 1992, Hueva, España, Diputación Provincial, pp. 103-183.

PAZOS, Manuel (1973). "Los misioneros franciscanos de México y la enseñanza técnica que dieron a los indios", en Archivo iberoamericano. Revista trimestral de estudios históricos publicada por los PP. Franciscanos, Madrid, año XXXIII, abril-septiembre de 1973, núms. 130-131.

RIESCO, Ángel (2000). Introducción a la paleografía y la diplomática general, Madrid: Síntesis, cap. 2, pp. 33-48.

RINALDINI, Benito (1994), Arte de la lengua tepehuana, con un vocabulario, confesionario y catecismo, publicado en 1743 en la imprenta de la viuda de José Bernardo de Hogal, edición facsimilar, CONACULTA-Gobierno del Estado de Durango.

SAHAGÚN, Bernardino de 1979. Códice Florentino, Edición facsimilar. México: Secretaría de Gobernación, III tomos (ejemplar numerado 101).

SAHAGÚN, Bernardino de 2002. Historia General de las Cosas de la Nueva España. López Austin, Alfredo (estudio introductorio). México: CONACULTA, Cien de México, III tomos.

TAPIA ZENTENO, Carlos de (1985). Paradigma apologético y noticia de la lengua huasteca: con vocabulario, catecismo y administración de sacramentos, Montejano y Aguinaga, Rafael (estudio bibliográfico y notas); Acuña, René (ed.). Mexico: UNAM, Instituto de Investigaciones Filológicas, p. 128.

THIEMER-SACHSE, Úrsula (2002). "Los complejos 'libros e imprenta' en el vocabulario español-zapoteco (1578) de Juan de Cordova". En: Castañeda, Carmen (coord.), Del autor al lector, México: Miguel Ángel Porrúa-Ciesas.

TORRE REVELO, José 1955. "Algunos libros de caligrafía usados en México en el siglo XVII”, en Historia Mexicana, V (oct.-dic.), pp. 220-227. 
TOVAR DE TERESA, Guillermo (1988). Un rescate de la fantasia: el arte de los Lagarto, iluminadores novohispanos de los siglos XVI y XVII. México: El Equilibrista-Turner.

VALTON, Emilio (1935). Impresos mexicanos del siglo XVI. México: Imprenta Universitaria, lámina XLVIII.

WHALLEY, Joyce (1982). The Pen's Excellencie. A Pictorical History of Western Calligraphy. New York: Taplinger.

WHITTAKER, Martha Ellen (1998). Jesuit Printing in Bourbon Mexico City: The Press of the Colegio de San Ildefonso, 1748-1767. California: University de Berkeley, tesis doctoral.

ZUBILlAGA, Félix (1958). Monumenta Mexicana, Roma, vol. V, Documento 213, pp. 702-722.

ZULAICA GÁRATE, Román (1991). Los Franciscanos y la imprenta en México en el siglo XVI. México: UNAM-IIB, 373 pp. 